\section{Role of monocyte chemotactic protein-3 and -4 in children with virus exacerbation of asthma}

\author{
J. Santiago*,\#,ף, J.L. Hernández-Cruz*, M.E. Manjarrez-Zavala*, R. Montes-Vizuet*, \\ D.P. Rosete-Olvera*, A.M. Tapia-Díaz*, H. Zepeda-Peney* and L.M. Terán*``
}

ABSTRACT: Macrophages play a crucial role in respiratory viral infections. However, the mechanisms by which these cells are recruited locally are not fully understood. The current authors studied the role of the chemokines monocyte chemotactic protein (MCP)-1, $-2,-3$ and -4 on monocyte/macrophage recruitment during respiratory viral infections. Levels of these chemokines were investigated in nasal aspirates from 6-12-yr-old children suffering from respiratory viral infections, caused by rhinoviruses, influenza viruses, parainfluenza viruses, adenoviruses and respiratory syncytial virus.

MCP-3 and -4 were significantly higher in samples derived from virus-infected children compared with samples from the same children when they had been asymptomatic. Concentrations of both chemokines were found to significantly correlate with the number of recruited nasal macrophages. Chemotaxis assays showed that purified MCP-3 and -4 from nasal aspirates showed biological activity in vitro. There were no significant differences in MCP-1 and -2 levels between both groups.

The present data indicates that monocyte chemotactic protein-3 and -4 may have an important role in macrophage recruitment in children with proven upper respiratory viral infections. These chemokines could be potential targets for therapeutic intervention in respiratory viral infections.

KEYWORDS: Macrophages, monocyte chemotactic protein-1, -2, -3 and -4, upper respiratory infections, viral infections

V iral infections are the major cause of the common cold and are recognised as a major health problem worldwide, particularly because a significant number of patients develop rhinosinusitis and/or asthma. Monocytes play important roles in respiratory viral infections [1]. For example, during infectious inflammatory processes, these cells migrate from the bloodstream into nasal tissue, where they mature into either macrophages or dendritic cells. In contrast to dendritic cells that transfer information from the periphery to the regional lymph nodes, tissue macrophages appear to exert their function in situ. These highly phagocytic cells play important roles in innate immunity by engulfing infectious agents and killing them through the action of the lysosomes. They also constitutively express major histocompatibility complex class II molecules and are thus able to instruct the adaptive immune system by presenting pathogen-derived peptides to local T-cells. In the case of viral infections, macrophages play crucial roles in virion phagocytosis and destruction, antigen presentation and cytokine production.
Studies conducted in mice have shown that under steady-state conditions about half of the circulating monocytes leave the bloodstream each day [2]. However, in mice responding to inflammatory challenge, the number of monocytes leaving the circulation per day is at least doubled. The half-life of circulating monocytes in humans is about three times longer than in mice, but the 1,000-fold greater monocyte mass in humans means that $\sim 340$ million monocytes leave the circulation each day [2]. Monocyte recruitment into the airways involves a series of events including adhesion to endothelial cells, transendothelial migration and subsequent chemotactic movement. These processes are regulated by the local release of inflammatory mediators and cytokines [3]. The monocyte chemotactic proteins (MCP)-1, $-2,-3$ and -4 have assumed particular significance in relation to these processes. The MCPs are members of the CC chemokine family and share $51-78 \%$ amino acid homology. The four MCPs activate monocytes via the CC chemokine receptor (CCR)2. MCP-3
AFFILIATIONS

*National Institute of Respiratory Diseases,

\#Postgraduate Programme of Biological Sciences, Facultad de Ciencias, Universidad Nacional Autónoma de Mexico, Mexico City, "Biomedicine in the Postgenomic Era, A.C., Mexico.

CORRESPONDENCE

L.M. Terán

National Institute of Respiratory Diseases

Calz. de Tlalpan 4502

Sección XVI

14080

México

Fax: 5556655700

E-mail: Imteran@iner.gob.mx

Received:

July 092007

Accepted after revision:

June 092008

\section{SUPPORT STATEMENT}

The present study was supported by the grant 45172, from the Consejo Nacional de Ciencia y Tecnología (CONACYT; Benito Juárez CP Mexico).

STATEMENT OF INTEREST None declared. 
and -4 additionally activate both CCR1 and CCR3, while MCP-2 activates CCR5 [4].

Naturally occurring common colds have been proved to be an excellent model for the investigation of inflammatory mechanisms in upper viral respiratory disease. Using this model the present authors have previously shown that interleukin (IL)-8, RANTES and macrophage inflammatory protein (MIP)- $1 \alpha$ are released in the nasal secretions from children suffering naturally from upper respiratory viral infection, suggesting that they may be important in the recruitment of neutrophils and eosinophils, respectively $[5,6]$. However, no studies have been carried out investigating the possible role of MCPs in naturally occurring colds. MCP-1, $-2,-3$ and -4 are also known as CC chemokine ligand (CCL)2, 8, 7 and 13, respectively.

\section{METHODS}

\section{Participants}

Between October 1999 and September 2001, 51 volunteers were recruited from 125 children on asthma registers kept in the National Institute of Respiratory Diseases (Mexico City, Mexico) from a longitudinal study on virus respiratory infection and asthma conducted in the school "Tizoc" Xochimilco, Mexico City, Mexico. A letter was sent to the parents of each child informing them of the study and inviting their children to participate. Every child was allocated a number, randomly. Most (95\%) children had a history of wheeze or cough in the 12 months before the study. The hospital's ethics committee approved the study. Written and verbal consent was obtained from parents and children.

\section{Procedures}

At study entry, participants' height and peak expiratory flow (PEF) rates were recorded. The children were shown the nasal aspirate sampling technique that would be used during the study.

Participants used a diary card to record the peak flow rates. Their atopic status was determined by skin-prick testing with different allergens (Dermatophagoides pteronnisinus and D. farinae, mixed grass, tree pollens, cat and dog dander and cockroach). They also recorded subjective assessments of respiratory symptoms as follows: 0: absent; 1 : mild; 2: moderate; and 3: severe. Upper respiratory tract symptoms were: runny nose, sneezing, blocked nose, sore throat, hoarse voice, headaches, aches or pains elsewhere, feeling a chill, fever, or shivers. Lower respiratory tract symptoms were: cough during the day, wheeze during the day, shortness of breath during the day, night cough, and wheeze or shortness of breath during the night. Scores were added to give daily upper and lower respiratory tract scores. When the upper respiratory tract score was $\geqslant 1$, a nasal aspirate was taken from the child, which was tested for the presence of a viral infection. Nasal aspirates were collected from the child within the first $18 \mathrm{~h}$ (range 12-24 h) of the outbreak of respiratory symptoms. The nasal aspirate was homogenised in nine volumes of virus transport medium and centrifuged at $2,500 \times g$ for $10 \mathrm{~min}$ at $10^{\circ} \mathrm{C}$. Supernatant was recovered and used for cytokine detection; the cell pellet was used to study the nasal recruited cells. Similar samples were obtained when the same children had been asymptomatic for $\geqslant 2$ weeks.

An upper respiratory tract infection was diagnosed when a participant reported a cold and infection was detected as described in virus detection methods. The start of infection was determined using plots of all recorded upper respiratory tract symptoms. Severity was assessed by the change in mean lower respiratory tract symptoms or PEF measurements (largest drop from the median expiratory flow rate) from the week before to the week after the start of infection.

\section{Virus detection methods}

Detection of rhinovirus (RV)-39 (RV-39) was performed by RTPCR as previously described [5]. Briefly, RNA was purified from $500 \mu \mathrm{L}$ of the original nasal sample with Trizol ${ }_{\circledR}$ (Invitrogen, Carlsbad, CA, USA) and reverse transcribed using Superscript ${ }^{\circledR}$ enzyme (Invitrogen) and oligo(dT) primer (Invitrogen). PCR was performed with Expand enzyme (Roche, Indianapolis, IN, USA). The oligonucleotide primer sequences were: sense 5'GCACTTCTGTTTCCCC3' and antisense 5'CGGACACCCAAAGTAG3', which generated a product size of $380 \mathrm{bp}$. Samples from all reported episodes and all asymptomatic samples were analysed in duplicate.

Detection of other respiratory viruses (adenovirus, parainfluenza virus, influenza virus type A, influenza virus type $\mathrm{B}$ and respiratory syncytial virus (RSV)) was performed by cell culture in cell lines including Vero, HEp-2 and Madin-Darby canine kidney cell monolayers. When cytopathic effects were extensive, detached cells were analysed using an immunofluorescence kit (3105; Chemicon, Temecula, CA, USA) [7].

\section{Differential cell counts}

Nasal cells obtained from nasal aspirate were resuspended in PBS $\left(10^{6}\right.$ cells $\left.\cdot \mathrm{mL}^{-1}\right)$. A $50-\mu \mathrm{L}$ aliquot of cells was subjected to cytocentrifugation (Wescor 7620; Wescor, Logan, UT, USA), airdried and stained with a Diff-Quick Stain kit (Dade Behring, Newark, DE, USA). In total, 400 cells per cytospin were counted.

\section{ELISA for detection of MCPs}

Concentrations of MCP-1, $-2,-3$ and -4 in nasal aspirates were measured using specific sandwich ELISAs as previously described [8]. Briefly, a pair of highly specific antibodies for each chemokine was purchased (R\&D Systems, Minneapolis, MN, USA) and an ELISA developed following the manufacturer's protocol. Measurements of MCP-3 and -4 were performed in neat (nonconcentrated) nasal aspirates while MCP-1 and -2 were measured in two-fold concentrated nasal aspirates, as these chemokines were not detected in neat samples. The lower limit of detection for all the MCP was $7 \mathrm{pg} \cdot \mathrm{mL}^{-1}$.

\section{Partial purification of MCP-3 and -4 from nasal aspirates}

Pooled nasal aspirates $(30 \mathrm{~mL})$ from 20 children with proven viral acute respiratory infections were applied to a HiTrap ${ }^{\circledR}$ column (Amersham, London, UK) coated with specific antibodies to MCP-3 and -4 (Chemicon). Bound MCP-3 and -4 were eluted, freeze-dried and redissolved in $1 \mathrm{~mL}$ of PBS, before applying onto a RP-8 reverse-phase column in an $\mathrm{HP}$ 1100 HPLC system (Agilent, Santa Clara, CA, USA). Eluted fractions were freeze-dried, redissolved in $0.1 \%$ bovine serum albumin, and subsequently assayed for monocyte chemotaxis.

\section{Chemotaxis assays}

Chemotaxis assays were performed in a microchamber (protocol AC482: Neuro Probe, Gaitherburg, MD, USA) using 

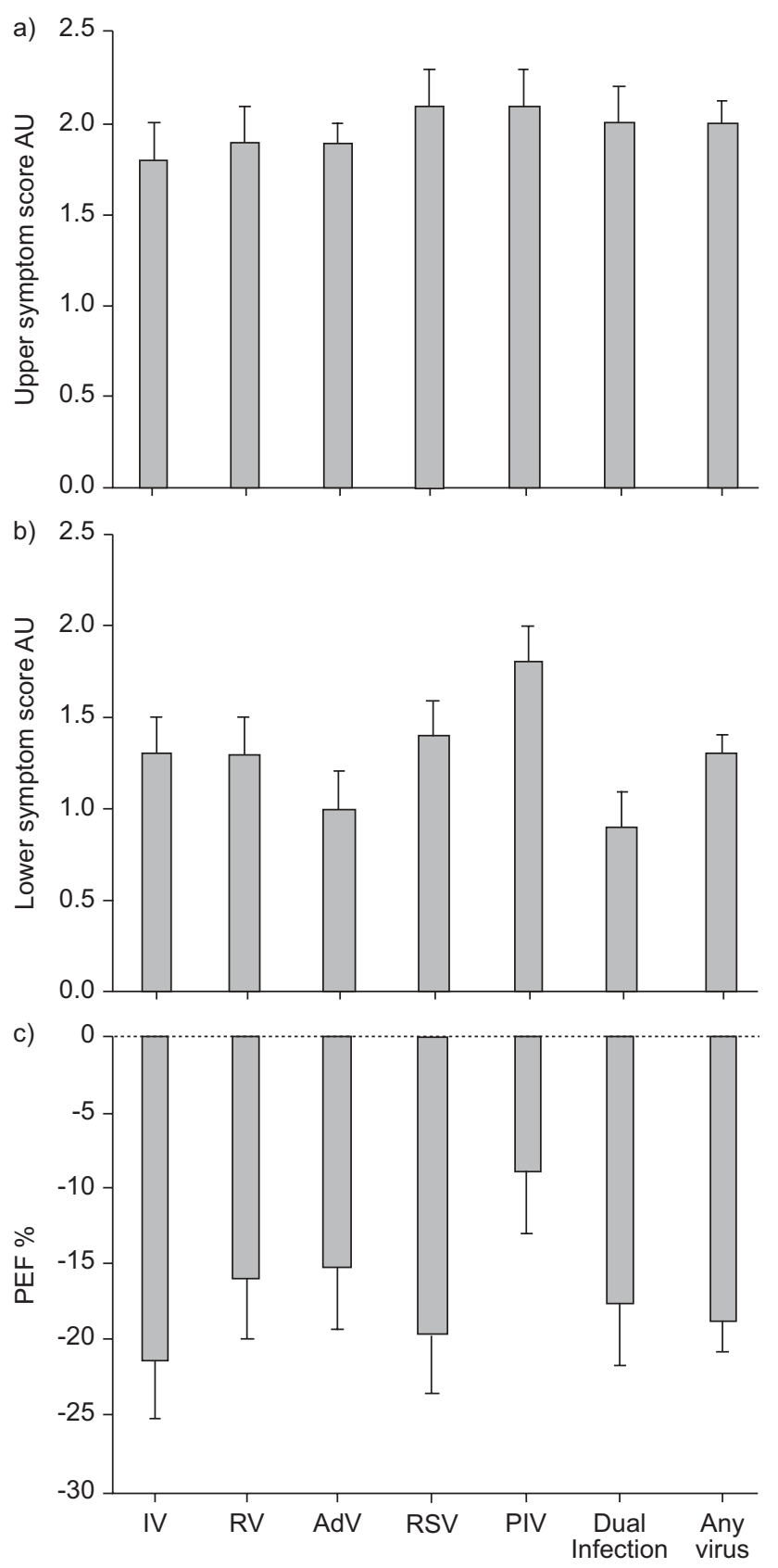

FIGURE 1. Mean change in a) upper and b) lower respiratory tract symptom scores and c) peak expiratory flow (PEF) rates in children during viral infection compared with children without viral infection. AU: arbitrary units; IV: influenza virus; RV: rhinovirus; Adv: adenovirus; RSV: respiratory syncytial virus; PIV: parainfluenza virus.

polycarbonate filters ( $5 \mu \mathrm{m}$; Poretics $\mathbb{E}$; Osmonics, Inc., Minnetonka, MN, USA) and human monocytes $\left(10^{6}\right.$ cells $\left.\cdot \mathrm{mL}^{-1}\right)$. Chamber was incubated for $90 \mathrm{~min}$ at $37^{\circ} \mathrm{C}$. Filter was removed, fixed and stained with Giemsa solution. Monocytes per five microscopic fields were counted at a $200 \times$ magnification.

\section{Statistical analysis}

The clinical data generated from the current study were coded and entered on to a database. The duration of an episode was

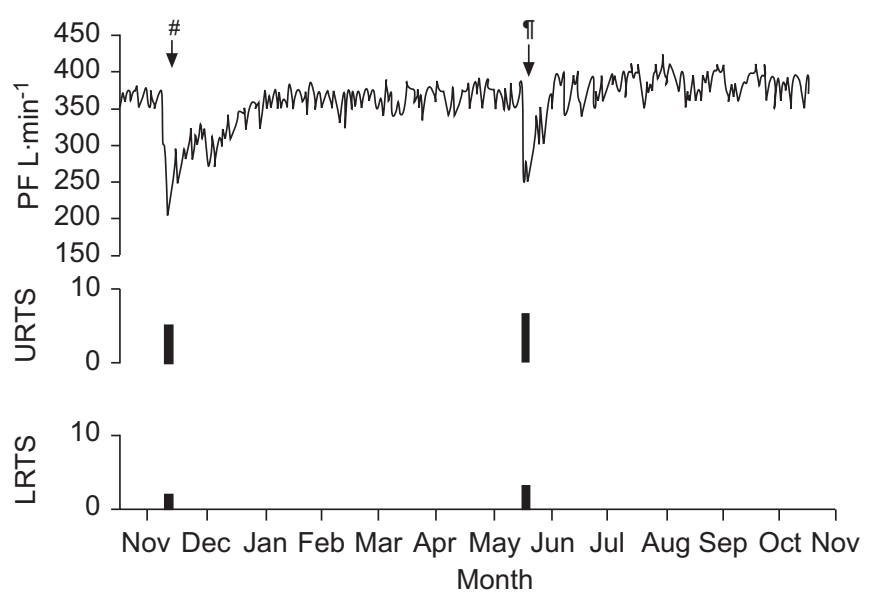

FIGURE 2. Chart showing virus identification, peak flow (PF), and respiratory symptom scores ( $\mathbf{\square})$ for a studied child. Samples were taken where indicated (arrows). LRTS: lower respiratory tract symptoms; URTS: upper respiratory tract symptoms. ${ }^{\# \text { : influenza A virus; " }}$ ": rhinovirus.

taken as the time from the initial fall in PEF and/or rises in symptoms to the day when they returned to the median value. Additionally, the infection was further confirmed as described in virus detection methods. The Mann-Whitney U-test was used to compare continuous data between subgroups. Different episodes in the same child were treated as independent. MCP levels were analysed by Kruskal-Wallis test. A pvalue $<0.05$ was regarded as statistically significant. Correlations between chemokine levels and cell counts were analysed using Spearman's rank sum testing.

\section{RESULTS}

From the 125 asthmatic children, 51 expressed an interest in participating in the study. The remaining 74 did not wish to participate. Reasons for declining participation included unwillingness to take part in a time-consuming study, domestic difficulties, emigration and the possibility that the project would interfere with school work.

Three children had outgrown their asthma, as reported by their parents. Thus, they were excluded from the study. The present study cohort included 18 males and 30 females (mean (range) age 10.15 (8.2-12.4) yrs). In total, 36 (75\%) children were atopic. Mean follow-up was 70 weeks (from November 1999 to June 2001, excluding the summer recess between July and August 2000). The mean (range) forced expiratory volume in one second (FEV1) at entry was $1.92(1.1-2.63) \mathrm{L}$ with a mean FEV $1 \%$ predicted of 76 (50-120)\% pred. A total of 15 children took bronchodilators regularly and 19 as required; 10 took prophylactic inhaled steroids. The median (range) baseline PEF was $342(170-572) \mathrm{L} \cdot \mathrm{min}^{-1}$.

There were a total of 89 reported cases of acute respiratory infections from the remaining 48 Mexican children: rhinovirus was detected in $24(26.97 \%)$, influenza A virus in $11(12.36 \%)$, adenoviruses in $11(12.36 \%)$, influenza B in eight $(8.99 \%)$, RSV in eight $(8.99 \%)$, parainfluenza virus type 2 in seven $(7.87 \%)$, parainfluenza virus type 3 in six $(6.74 \%)$, parainfluenza virus type 1 in three $(3.37 \%)$, and $11(12.36 \%)$ of dual infection. 


\begin{tabular}{|c|c|c|}
\hline TABLE 1 & $\begin{array}{l}\text { Differential and tota } \\
\text { fluids from children } \\
\text { infection or asympt }\end{array}$ & $\begin{array}{l}\text { unts in nasal aspirate } \\
\text { ven viral respiratory }\end{array}$ \\
\hline Cells & Asymptomatic ${ }^{\#}$ & Symptomatic \\
\hline Neutrophils & $11(4-25)$ & $2350^{\star * \star}(35-12600)$ \\
\hline Macrophages & $1.5(0.8-6)$ & $148^{\star \star \star}(0-2280)$ \\
\hline Lymphocytes & $1.2(0.6-8.0)$ & $188^{\star \star \star}(0-1860)$ \\
\hline Eosinophils & $0.08(0-1.20)$ & $12(0-108)$ \\
\hline Epithelial & $10.5(5-17)$ & $24^{\star \star \star}(0-476)$ \\
\hline Total & $24(6-29)$ & $2600 * * *(40-13800)$ \\
\hline
\end{tabular}

Children developed a mean \pm SD $1.97 \pm 0.169$ respiratory viral infections over the study period.

Median (range) lower respiratory-tract scores in the week before and after infection were $0.3(0-2)$ and $1.9(0-8)$, respectively. Inspection of the charts for each child showed that viral infections were associated with sudden severe falls in PEF, followed by recovery to baseline again over the following 2-3 weeks (fig. 1). Median (range) PEF rates in the weeks before and after infection were $310(108-458) \mathrm{L} \cdot \mathrm{min}^{-1}$ and 259 (48-420) L. $\mathrm{min}^{-1}$, respectively.
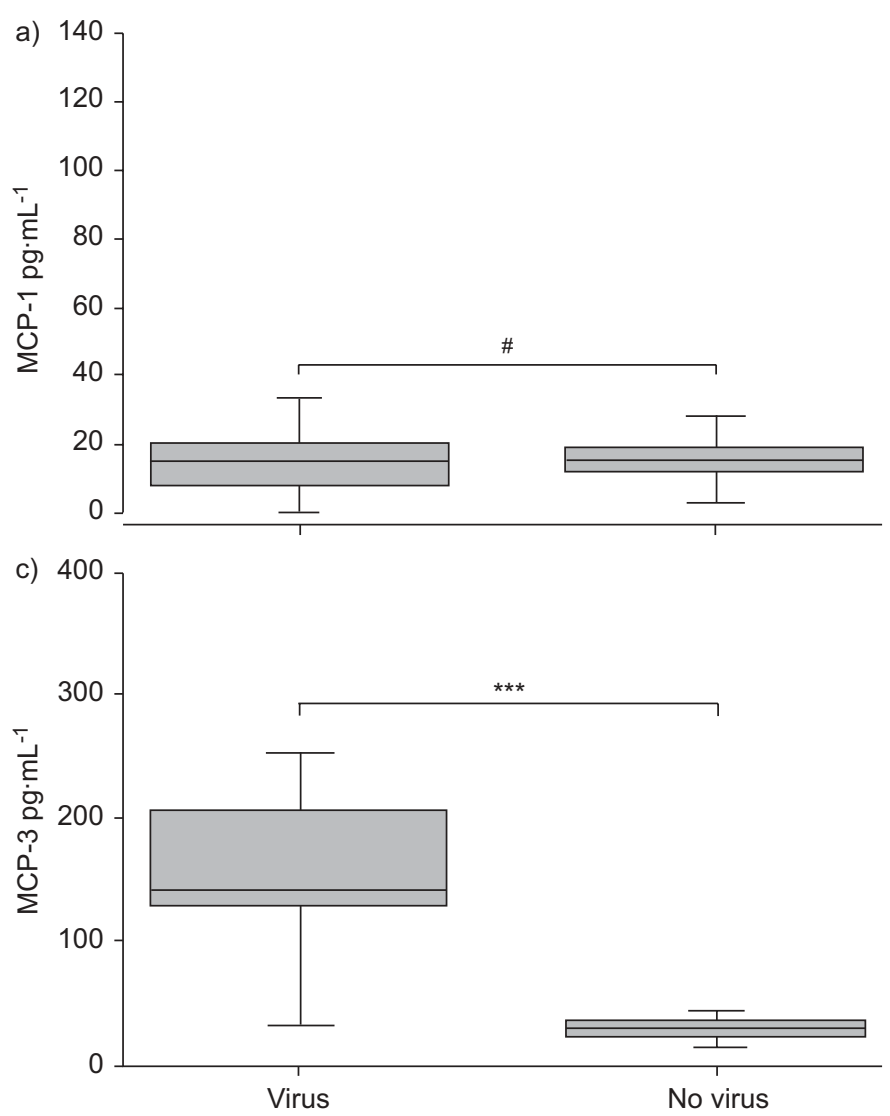

The severity of lower respiratory tract symptoms was increased and PEF measurements dropped with all respiratory virus types. The relationship of lower respiratory tract scores was significant for all virus types (fig. 1d). Peak flows dropped on average by $16.22 \pm 1.80 \%\left(55.56 \pm 5.7 \mathrm{~L} \cdot \mathrm{min}^{-1}\right)$ during viral episodes. Figure 2 shows respiratory symptoms, peak flow recordings and viruses isolated for one child.

\section{Cell counts}

The total numbers of cells recorded during a symptomatic period were nearly 100 -fold higher when compared with the asymptomatic period; median (range) values were 2,600 (40$13,800) \times 10^{3}$ cells $\cdot \mathrm{mL}^{-1}$ and $24(6-29) \times 10^{3}$ cells $\cdot \mathrm{mL}^{-1}$, respectively. All cell types were found to be increased in the symptomatic group (neutrophils, 200-fold; macrophages, 100fold; and lymphocytes, 150-fold; table 1) compared with the asymptomatic group; differences were statistically significant $(p<0.001)$. Eosinophils were seen in very few samples and there was no significant difference between the two groups.

\section{Measurements of MCPs in nasal secretions}

Measurements of MCPs by ELISA showed no changes in levels of both MCP-1 $\left(22.9 \pm 6.1\right.$ versus $\left.16.4 \pm 1.3 \mathrm{pg} \cdot \mathrm{mL}^{-1}\right)$ and MCP-2 $\left(11.85 \pm 4.1\right.$ versus $\left.7.2 \pm 1.2 \mathrm{pg} \cdot \mathrm{mL}^{-1}\right)$ in nasal aspirates from children with naturally occurring acute respiratory infections as compared with samples from the same children when they had been asymptomatic (fig. 3a and b). In contrast, MCP-3 and -4 were increased in nasal aspirates from children with acute
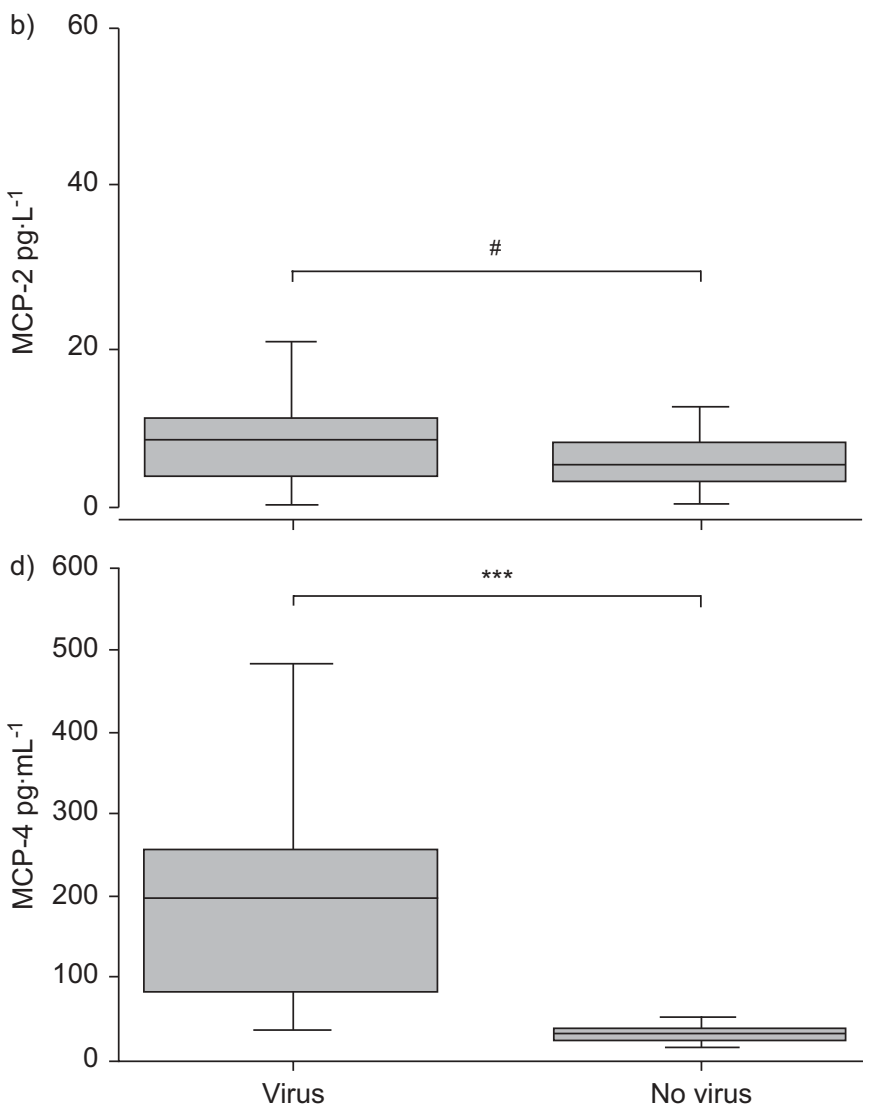

FIGURE 3. Monocyte chemotactic protein (MCP) levels in nasal aspirates from 81 children with proven viral respiratory infections compared with 51 children without viral infections. $^{\# \text { : } \text { nonsignificant; }}{ }^{* * *}: \mathrm{p}<0.001$. 

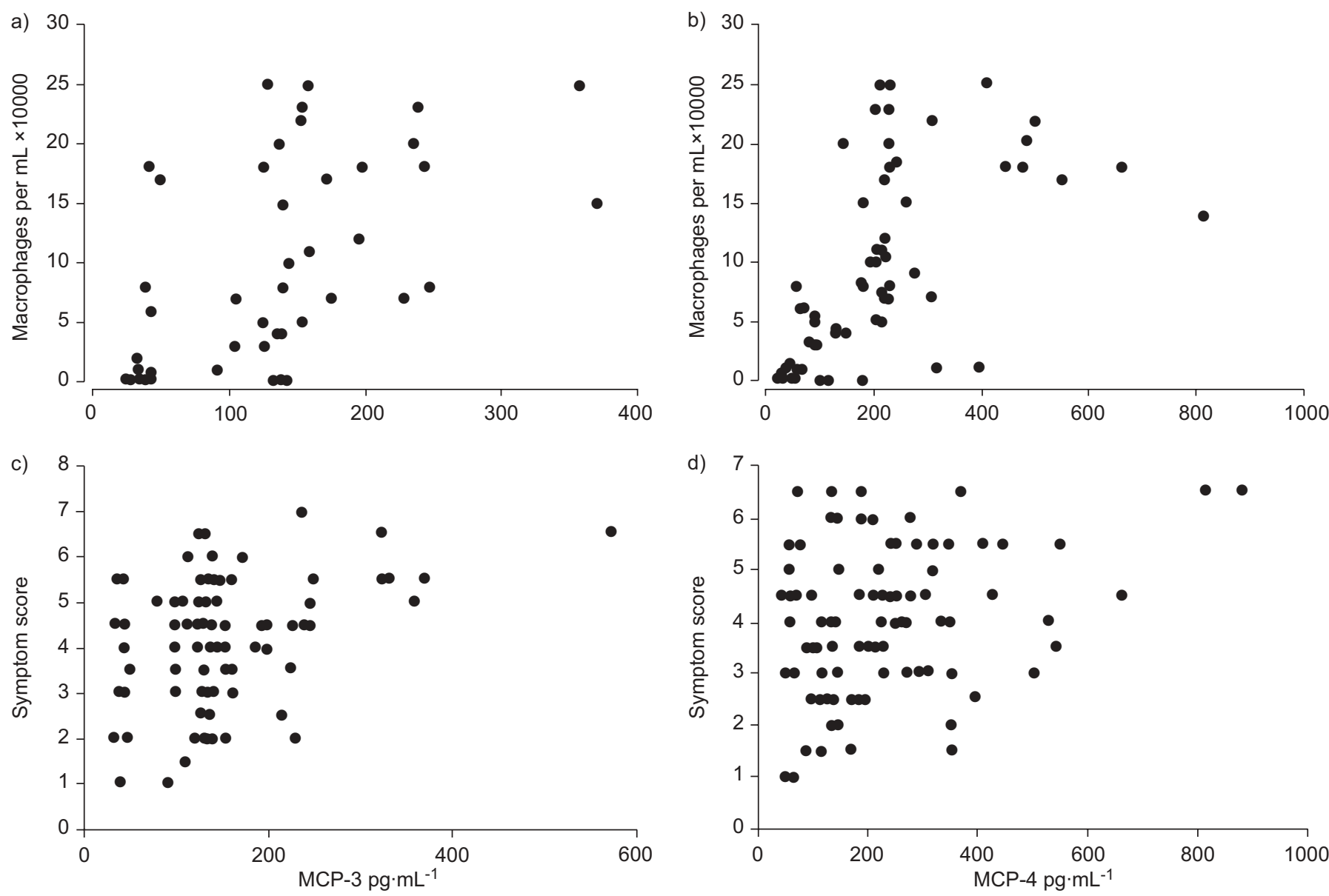

FIGURE 4. Correlations between macrophage numbers and monocyte chemotactic protein (MCP)-3 (a) and -4 (b) levels in nasal aspirate samples for children with proven viral respiratory infection. a) $r=0.654, p=0.003$; b) $r=0.648, p=0.003$. Correlation between upper respiratory symptoms and MCP-3 (c) and -4 (d) levels. c) $r=0.231$, $p=0.069 ; d) r=0.204, p=0.058$. Statistical analysis was performed using Spearman's rank sum test.

respiratory infections compared with the control samples (MCP-3: $\quad 185.0 \pm 17.1$ versus $32.0 \pm 0.78 \mathrm{pg} \cdot \mathrm{mL}^{-1}$; $\mathrm{MCP}-4$ : $243.2 \pm 18.67$ versus $33.8 \pm 1.56 \mathrm{pg} \cdot \mathrm{mL}^{-1}$; fig. $3 \mathrm{c}$ and $\mathrm{d}$; $\mathrm{p}<0.001$ ). All respiratory viruses, including $R V$, influenza virus, parainfluenza virus and RSV induced comparable concentrations of MCP-3 and -4 in nasal secretions (data not shown).

In order to investigate the relationship between macrophage influx and MCPs, correlations between macrophage counts and MCP-3 and -4 levels were sought. Levels of either MCP-3 or -4 correlated with macrophage numbers recruited in nasal samples from children with respiratory viral infections $(\mathrm{r}=0.654$; $\mathrm{p}=0.003$; and $\mathrm{r}=0.648 ; \mathrm{p}=0.003$, respectively; fig. $4 \mathrm{a}$ and $\mathrm{b}$ ). Moreover, levels of both chemokines showed a trend towards a significant correlation with upper respiratory symptoms $(\mathrm{r}=0.231 ; \mathrm{p}=0.069 ;$ and $\mathrm{r}=0.204 ; \mathrm{p}=0.058$, respectively).

\section{Biochemical and biological characterisation of MCP-3 and -4 from nasal aspirate samples}

Having demonstrated increased MCP-3 and -4 immunoreactivities associated with upper respiratory infections, the present authors then investigated whether these chemokines were biologically active in vitro. Thus, $1.5 \mathrm{~mL}$ of nasal aspirates from each one of 20 reported acute respiratory infection episodes were combined and MCP-3 and -4 were purified by specific anti-MCP affinity chromatography and reverse phase HPLC. Figure 5 shows that monocyte chemotactic activities resolved as two peaks at 22 and $31 \mathrm{~min}$. It was demonstrated by ELISAs that peak one corresponded to MCP-3, while peak two corresponded to MCP-4 (105 and $301 \mathrm{pg} \cdot \mathrm{mL}^{-1}$, respectively).

\section{DISCUSSION}

The present study is the first demonstrating that children suffering from naturally occurring viral infection release high concentrations of MCP-3 and -4 into the nasal secretions. Levels of both chemokines showed a significant correlation with macrophage numbers, suggesting that they may contribute to their recruitment in vivo. Indeed, partial purification of MCP-3 and -4 by HPLC and affinity chromatography showed that they are biologically active on monocytes in chemotaxis assays. In contrast, concentrations of MCP-1 and -2 were not significantly different between virus infected and noninfected children.

MCP-1 to -4 are potent monocyte/macrophage attractants and show $58-71 \%$ homology. Among all MCPs, MCP-1 is the only cytokine that has been studied in viral respiratory infection. For example, BECKER and SOUKUP [9] reported that RSV 


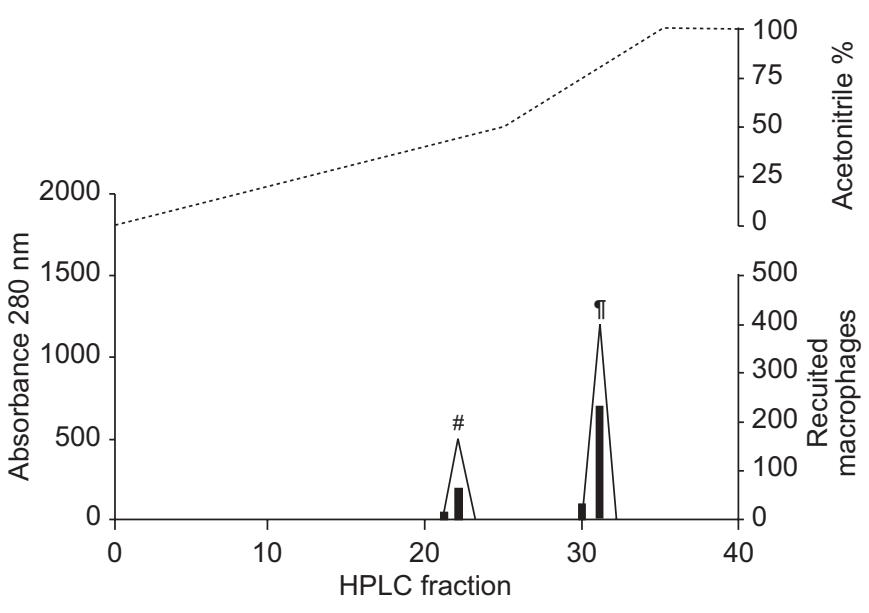

FIGURE 5. Monocyte chemotactic activities in nasal aspirate using HPLC. Material eluted from the anti-monocyte chemotactic protein (MCP)-3 and -4 affinity column was applied to a reverse-phase chromatograph, and bound material was washed from the column using two-step linear gradient of acetonitrile $(\cdots \cdots)$ over a 40-min period. Monocyte chemotaxis to individual fractions is given as the number of monocytes chemoattracted per area ( $\mathbf{\square})$. Two monocyte chemotactic activities were identified, which eluted at $22 \mathrm{~min}$ and $31 \mathrm{~min}$, respectively. By ELISA they were found to correspond to MCP-3 $\left(^{\#}\right)$ and $-4\left({ }^{\circ}\right)$, respectively.

stimulated the release of MCP-1 from monocytes co-cultured with airway epithelial cells in vitro, while NOAH and BECKER [10] have shown that experimentally induced RSV infection in volunteers stimulates MCP-1 production in their upper airways. However, none of MCPs has been investigated in naturally occurring viral respiratory infections.

The present study has demonstrated that naturally occurring upper respiratory viral tract infections induce the release of the chemokines MCP-3 and -4 into the airways of $8-12-y r-o l d$ children. Interestingly, concentrations of both chemokines correlated with the macrophage numbers, suggesting that they may be involved in the recruitment of these cells. Indeed, the present finding that nasal MCP-3 and -4 induces monocyte migration in vitro further supports this hypothesis. To the current authors' knowledge, these are the first data indicating that MCP-3 and -4 may be involved in the pathogenesis of respiratory viral infections.

While MCP production occurs in the context of virus infection, the mechanisms underlying this event are not well understood. Some respiratory viruses, such as adenovirus and cytomegalovirus, have been shown to have transactivating factors capable of increasing the expression and synthesis of cytokines relevant to asthma in monocytes/macrophages and lymphocyte cell lines $[11,12]$. RV-39 are also capable of activating cytokine promoters (IL-6), acting chiefly via nuclear factor (NF)-кB [13]. In the MCP genes there are several potential binding sites for transcription factors, including activator protein-1 and NF- $\kappa B$ [14-16]. Indeed, it has been shown that blocking NF-kB, using pyrrolidine dithiocarbamate, reduces MCP-3 production. [14]. The precise mechanisms by which viruses induce MCP-3 and -4 synthesis during naturally occurring colds have yet to be determined.
In contrast to the former chemokines, neither MCP-1 nor MCP -2 were elevated during naturally occurring colds (neither in neat nor in concentrated nasal aspirates). In a previous report, NOAH and BECKER [10] have shown increased levels of MCP-1 in nasal washings derived from RSV experimentally infected subjects. In the present study, levels of MCP-1 were raised significantly in nasal washings 6 days after inoculation with $\mathrm{RSV}$, peaking at 7 days. A similar profile of MCP-1 release has been reported by POWER et al. [17] in an animal study which was conducted in mice exposed to phormalin-inactivated RSV. In the latter study, mice were sacrificed 5 and 7 days after inactivated-RSV inoculation. Consistent with the study by NOAH and BECKer [10], POWER et al. [17] showed that MCP-1 was upregulated on day 7 but not on day 5 , while MCP-3 was highly upregulated at day 5, which suggests that the MCPs may have different kinetics of release. In the present study, nasal secretions in children were taken during early phases of the virus infection (12-24 h of developing clinical symptoms), which may explain the low levels of MCP-1 found in nasal secretions. Thus, future studies must investigate the kinetics of release of the MCPs in naturally occurring colds.

Because in previous studies the current authors' group and others have reported that the monocytes/macrophage attractants RANTES/CCL5 and MIP-1 $\alpha$ /CCL3 are released into the upper airways of patients suffering naturally occurring colds $[6,18]$, these chemokines were not investigated in the present study. Instead, it focused on the MCPs that have not been previously investigated. Thus, MCP-3 and -4 , together with RANTES and MIP- $1 \alpha$, may orchestrate monocyte/macrophage recruitment into the upper airways of patients suffering from viral infection.

The four MCPs activate monocytes via CCR2, which is a major receptor expressed in both monocytes and macrophages [19]. Thus, it may not be relevant that MCP-1 and -2 were not increased, as both MCP-3 and -4, will activate these cells through CCR2. These two chemokines also activate eosinophils via CCR3. However, in the present study there was no difference in eosinophil numbers between the two groups. A previous study has shown that $\mathrm{CCR}^{-/-}$mice are protected from early pathological manifestation of influenza infection because of defective monocyte/macrophage recruitment [20]. Thus, it is tempting to hypothesise that the use of CCR2 antagonists may have therapeutic effects. It is now well established that respiratory viruses cause exacerbations of asthma and, consistent with this observation, the present authors found that virus-infected children showed a significant drop in peak flow. The development of CCR2 antagonists that could be used in clinical trials will define the role of these chemokines on common cold and virus exacerbations of asthma.

In summary, the present study has demonstrated that the monocyte chemotactic protein- 3 and -4 chemokines are found in increased concentrations in nasal secretions of children suffering from respiratory viral infections. Levels of these chemokines correlated with macrophage numbers and these cytokines, when purified from clinical samples, showed biological activity in vitro, suggesting that they may be involved in the activation and migration of monocyte/macrophages. The development of clinical efficient CC chemokine receptor 2 antagonists that neutralise monoctye chemotatic protein -3 and -4 may have 
therapeutic effects on common cold and virus exacerbations of asthma.

\section{ACKNOWLEDGEMENTS}

The authors are grateful to C. Arias (Instituto de Biotecnologia UNAM, Cuernavaca, Mexico) and A. Pardo (Facultad de Ciencias UNAM, Mexico City, Mexico) for advice on the experimental design of the study; to E. Valencia-Maqueda and A. Vega-Miranda (INER, Mexico City, Mexico) for technical assistance; and F. Fuentes-Arenas (INER) for sample collection.

\section{REFERENCES}

1 Message SD, Johnston SL. The immunology of virus infection in asthma. Eur Respir J 2001; 18: 1013-1025.

2 Muller WA. New mechanisms and pathways for monocyte recruitment. J Exp Med 2001; 194: F47-F51.

3 Luster AD, Alon R, von Andrian UH. Immune cell migration in inflammation: present and future therapeutic targets. Nat Immunol 2005; 12: 1182-1190.

4 Sozzani S, Zhou D, Locati M, et al. Receptors and transduction pathways for monocyte chemotactic protein-2 and monocyte chemotactic protein-3 similarities and differences with MCP-1. J Immunol 1994; 152: 3615-3622.

5 Teran LM, Johnston SL, Schröder J, Church MK, Holgate ST. Role of nasal interleukin-8 in neutrophil recruitment and activation in children with virus-induced asthma. Am J Respir Crit Care Med 1997; 155: 1362-1366.

6 Teran LM, Seminario MC, Shute JK, et al. RANTES, macrophage-inhibitory protein $-1 \alpha$, and the eosinophil product major basic protein are released into upper respiratory secretions during virus-induced asthma exacerbations in children. J Infect Dis 1999; 179: 677-681.

7 Manjarrez ME, Rosete DP, Rincón M, Villalba J, Cravioto A, Cabrera R. Comparative viral frequency in Mexican children under 5 years of age with and without upper respiratory symptoms. J Med Microbiol 2003; 52: 579-583.

8 Rojas-Ramos E, Avalos AF, Perez-Fernandez L, CuevasSchacht F, Valencia-Maqueda E, Teran LM. Role of the chemokines RANTES, monocyte chemotactic proteins-3 and -4 , and eotaxins- 1 and -2 in childhood asthma. Eur Respir J 2003; 22: 310-316.

9 Becker S, Soukup JM. Airway epithelial cell-induced activation of monocytes and eosinophils in respiratory syncytial viral infection. Immunobiology 1999; 201: 88-106.
10 Noah TL, Becker S. Chemokines in nasal secretions of normal adults experimentally infected with respiratory syncytial virus. Clin Immunol 2000; 97: 43-49.

11 Weitraub S, Dean DC. Interaction of a common factor with ATF, Sp1 or TATAA promoter elements is required for these sequences to mediate transcription by the adenoviral oncogene E1A. Mol Cell Biol 1992; 12: 512-517.

12 Crump JW, Geist LJ, Auron PE, Webb AC, Stinski MF, Hunninghake GW. The immediate early genes of human cytomegalovirus require only proximal promoter elements to upregulate expression of interleukin-1ß. Am J Respir Cell Mol Biol 1992; 6: 674-677.

13 Zhu Z, Tang W, Ray A, et al. Rhinovirus stimulation of interleukin-6 in vivo and in vitro. Evidence for nuclear factor $\kappa \mathrm{B}$-dependent transcriptional activation. J Clin Invest 1996; 97: 421-430.

14 Wuyts WA, Vanaudenaerde BM, Duupont LJ, Demedts MG, Verleden GM. Involvement of p38 MAPK, JNK, p42/p44 ERK and NF- $\kappa B$ in IL-1 $\beta$-induced chemokine release in human airway smooth muscle cells. Respir Med 2003; 97: 811-817.

15 Grassl GA, Fessele S, Merfort I, et al. Sesquiterpene lactones inhibit Yersinia invasion protein-induced IL-8 and MCP-1 production in epithelial cells. Int $J$ Med Microbiol 2005; 295: 531-538.

16 Cullen JP, Sayeed S, Jin Y, et al. Ethanol inhibits monocyte chemotactic protein-1 expression in interleukin-1 $\beta$-activated human endothelial cells. Am J Physiol Heart Circ Physiol 2005; 289: H1669-H1675.

17 Power UF, Huss T, Michaud V, Plotnicky-Gilquin H, Bonnefoy JY, Nguyen TN. Differential histopathology and chemokine gene expression in lung tissues following respiratory syncytial virus (RSV) challenge of formalininactivated RSV- or BBG2Na-immunized mice. J Virol 2001; 75: 12421-12430.

18 Bonville CA, Rosenberg HF, Domachowske JB. Macrophage inflammatory protein $-1 \alpha$ and RANTES are present in nasal secretions during ongoing upper respiratory tract infection. Pediatr Allergy Immunol 1999; 10: 39-44.

19 Rollins BJ. Chemokines. Blood 1997; 90: 909-928.

20 Dawson TC, Beck MA, Kuziel WA, Henderson F, Maeda N. Contrasting effects of CCR5 and CCR2 deficiency in the pulmonary inflammatory response to influenza A virus. Am J Pathol 2000; 156: 1951-1959. 